\title{
D-Luciferin, derivatives and analogues: synthesis and in vitro/in vivo luciferase-catalyzed bioluminescent activity
}

\author{
Giuseppe Meroni, Mehdi Rajabi and Enzo Santaniello* \\ Department of Medicine, Surgery and Dentistry and Centre of Molecular and Cellular Imaging \\ (IMAGO), Facoltà di Medicina e Chirurgia, Università degli Studi di Milano \\ clo Ospedale S. Paolo - Via A. di Rudini, 8- 20142 Milano, Italy \\ E-mail: enzo.santaniello@unimi.it
}

\begin{abstract}
D-luciferin is the natural substrate of all luciferases that catalyze the production of light in bioluminescent insects. The present review covers the synthesis of D-luciferin and derivatives or analogues that are substrates or inhibitors of the luciferase from the American firefly Photinus pyralis, the enzyme more frequently used in techniques of in vitro and optical imaging.
\end{abstract}

Keywords: D-luciferin, luciferase, synthesis, bioluminescence, optical imaging

\section{Contents}

1. Introduction

2. Synthesis of D-luciferin

3. D-luciferin analogues and derivatives as inhibitors of PpyLuc

3.1 D-luciferin analogues and derivatives

3.2. Benzothiazoles structurally related to D-luciferin

3.3 Dehydroluciferin

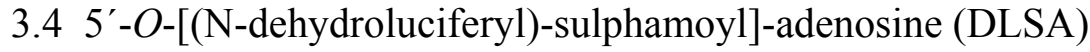

4. Analogues and derivatives of D-luciferin as substrates of luciferases for production of bioluminescence

4.1. Firefly luciferases: the mechanism of light emission

4.2. Bioluminescence and optical imaging

4.3. Colour-tuning of bioluminescence by modification of D-luciferin structure

4.3.1. Modifications of the thiazoline ring

4.3.2. Introduction of substituents in the benzothiazole moiety of D-luciferin

4.3.3. D-luciferin analogues bearing an aromatic moiety different from benzothiazole

4.4. 6'-Aminoluciferin derivatives: a new opportunity for bioluminescent assays and imaging

5. Conclusions 


\section{Introduction}

D-luciferin [(S)-2-(6'-hydroxy-2'-benzothiazolyl)thiazoline-4-carboxylic acid, 1] is the natural substrate of the enzyme luciferase (Luc), that catalyzes the production of the typical yellowgreen light of fireflies. ${ }^{1}$ Fireflies are only a part of the big family of bioluminescent insects that can emit light with wavelengths going from yellow-green $(560 \mathrm{~nm})$ to red $(620 \mathrm{~nm}){ }^{2}$ All the enzymes use the same substrate, i.e. D-luciferin (1). Therefore, only subtle differences in the architecture of Luc active sites may account for shifting the light wavelength. Specifically, firefly luciferases can modulate the proportion of green and red bioluminescence through a $\mathrm{pH}-$ sensitive mechanism. ${ }^{3}$ The luciferase from the North American firefly Photinus pyralis (PpyLuc) is a well characterized enzyme that finds a large number of applications in mammalian cells. PpyLuc has been used in living animals as a transgenic marker or as a tag for cells that have been transplanted. ${ }^{4}$ Due to its bioluminescence characteristics, PpyLuc is at present the most used enzyme in optical molecular imaging ${ }^{5}$ and is the most studied enzyme of the luciferase family. The results of such investigations have been a basis for understanding the complex mechanism ruling light emission in bioluminescence. PpyLuc binds its substrate D-luciferin (1) in its active site and catalyzes the formation of luciferyl adenosine monophosphate (2), in this respect behaving as an acyl-adenylate synthetase. ${ }^{6}$ Initiated by reaction of $\mathrm{O}_{2}$ with the thiazoline ring, a dioxyethanone intermediate is formed through the so called intramolecular chemically initiated electron-exchange luminescence (CIEEL). ${ }^{7}$ In the final step, detachment of $\mathrm{CO}_{2}$ generates the product oxyluciferin (3) in an electronically excited state, which produces a yellow-green light with a broad emission spectrum with a peak at $560 \mathrm{~nm}$ (Figure 1).

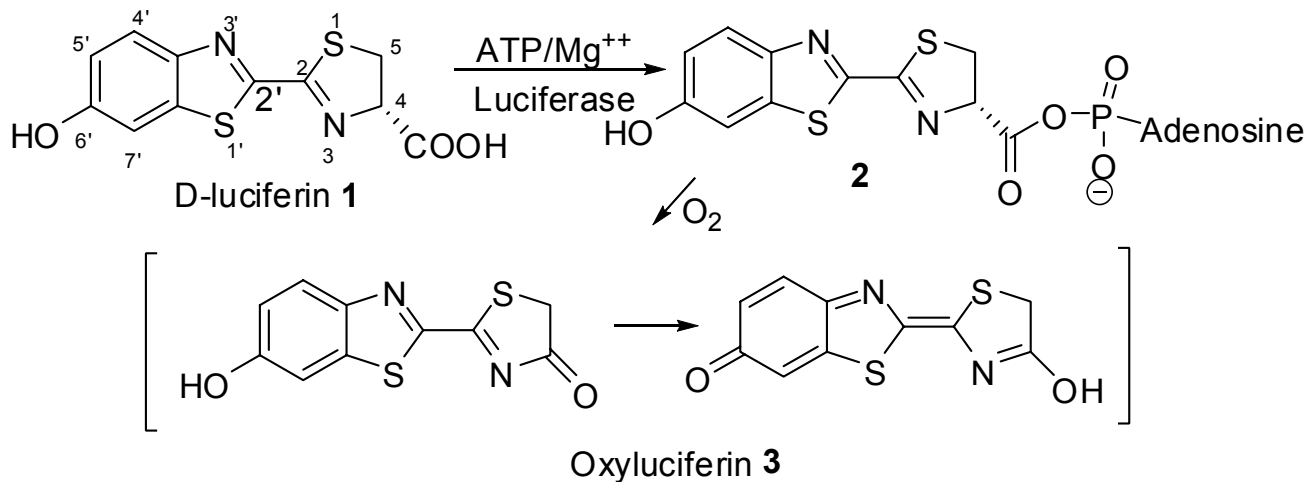

Figure 1. Luciferase-catalyzed transformation of D-luciferin (1) into oxyluciferin (3).

The present review will cover synthetic approaches to D-luciferin (1), its derivatives, and analogues that are substrates of PpyLuc and can show bioluminescence. Also inhibitors of Luc, structurally related to compound $\mathbf{1}$, will be described in order to highlight the competition of such compounds with D-luciferin and the interference that they can play in the bioluminescence process. 


\section{Synthesis of D-luciferin}

The chemical structure of D-luciferin (1), isolated from firefly tails, was proposed in $1961^{8}$ and later confirmed by synthesis. ${ }^{9}$ In this procedure, $p$-anisidine (4) is the starting material that, through intermediates 5 and $\mathbf{6}$, is transformed into the thioacid 7, in turn cyclized to 6methoxybenzothiazole-2-carboxylic acid (8). From this benzothiazole derivative, 2-cyano-6hydroxybenzothiazole (12) is prepared in four steps. Compound $\mathbf{1 2}$ is the key intermediate for the synthesis of $\mathbf{1}$, that can be obtained almost quantitatively by reaction with D-cysteine, in situ produced by reduction of D-cystine (Scheme 1).
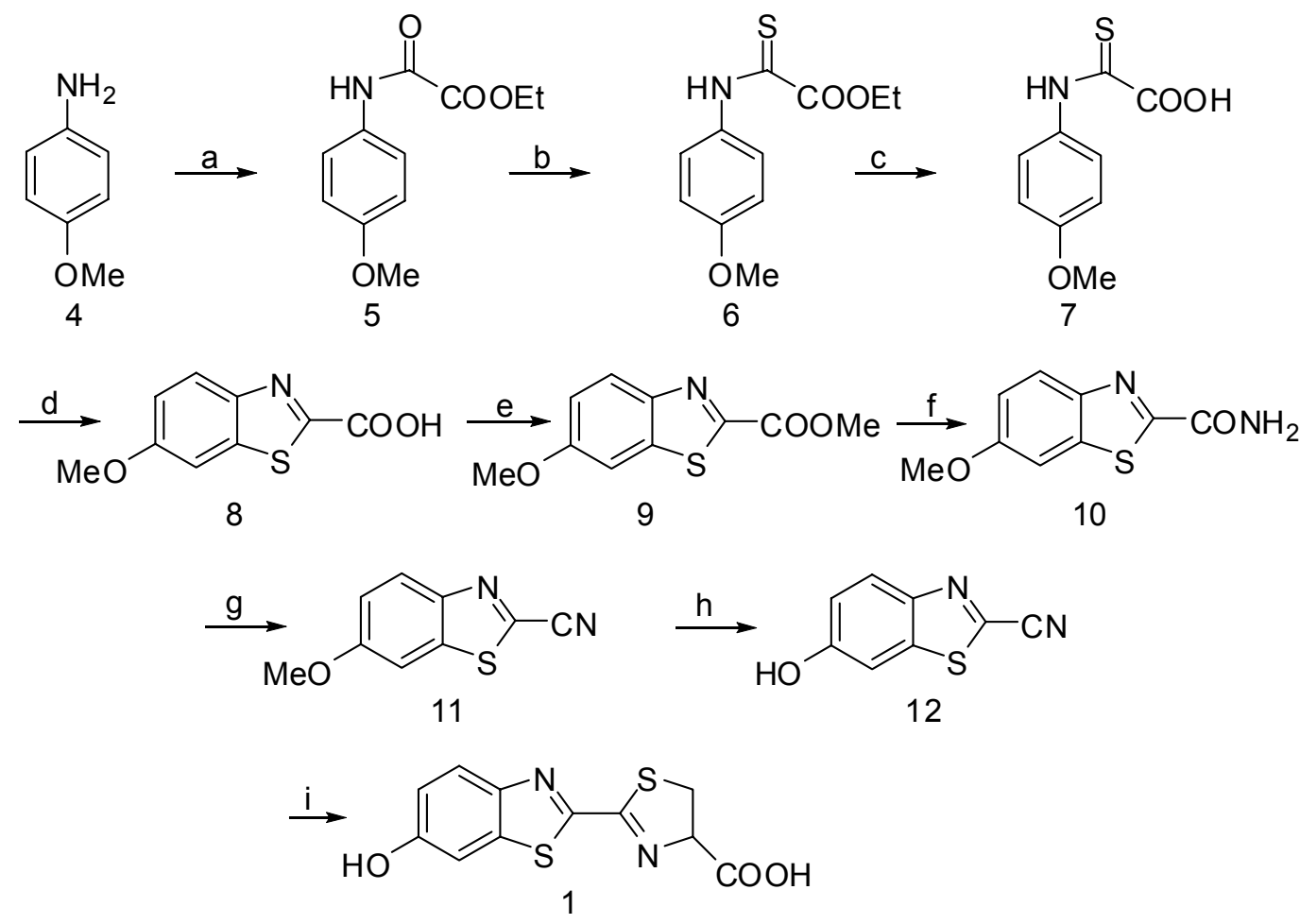

Scheme 1. Synthesis of D-luciferin (1) from $p$-anisidine (4). ${ }^{9}$ Reagents and conditions: (a) ethyl oxalate, $180{ }^{\circ} \mathrm{C}, 5 \mathrm{~min}, 58 \%$; (b) $\mathrm{P}_{2} \mathrm{~S}_{5}$, reflux, $40 \mathrm{~min}$; (c) $\mathrm{NaOH}, 0{ }^{\circ} \mathrm{C}$ then $\mathrm{HCl}$; (d) $\mathrm{K}_{3} \mathrm{Fe}(\mathrm{CN})_{6} / \mathrm{OH}^{-},<10{ }^{\circ} \mathrm{C}, 15 \mathrm{~min}$; (76\% crude, no isolation in steps b-d); (e) $\mathrm{CH}_{2} \mathrm{~N}_{2}, 0{ }^{\circ} \mathrm{C}, 15$ min, 40\%; (f) anhydrous $\mathrm{NH}_{3} / \mathrm{MeOH}$, heat, $30 \mathrm{~min}, 100 \%$; (g) $\mathrm{POCl}_{3}$, reflux, $15 \mathrm{~min}, 56 \%$; (h) PyHCl, $200{ }^{\circ} \mathrm{C}, 1 \mathrm{~h}, 62 \%$; (i) D-cysteine (in situ from D-cystine/liquid $\mathrm{NH}_{3} / \mathrm{Na}$, r.t., $10 \mathrm{~min}$ ) and 12 in $\mathrm{H}_{2} \mathrm{O} / \mathrm{MeOH}$, r.t., 0.5 h, $94 \%$.

The overall yield of D-luciferin (1) from $p$-anisidine (4) is $9 \%$ through nine steps. It should be pointed out that the synthetic approach described by White et al. is basically still used for the preparation of $\mathbf{1}$ and related compounds. ${ }^{10}$ As previously stated, 2-cyano-6hydroxybenzothiazole (12) is the key intermediate for the synthesis of $\mathbf{1}$ and the most reliable procedure to obtain this compound is the demethylation of 2-cyano-6-methoxy derivative $\mathbf{1 1}$. 
This reaction can be most efficiently accomplished by fusion at $220{ }^{\circ} \mathrm{C}$ with pyridinium hydrochloride (Py.HCl). ${ }^{9}$ In these conditions, the labile 2-nitrile moiety is kept intact and alternative procedures lead to hydrolysis of the cyano group. ${ }^{11}$ Other two procedures are described for the synthesis of 2-cyano-6-methoxybenzotiazole (11). According to Seto et al., ${ }^{12} 6$ methoxybenzothiazole-2-carboxyamide (10) is prepared from the 4-methoxythioxanilinamide $\mathbf{1 3}$ by oxidative cyclization with alkaline $\mathrm{K}_{3}\left[\mathrm{Fe}(\mathrm{CN})_{6}\right]$. The transformation of compound $\mathbf{1 0}$ into the nitrile $\mathbf{1 1}$ has been carried out essentially as reported by White et al. ${ }^{9}$ (Scheme 2).

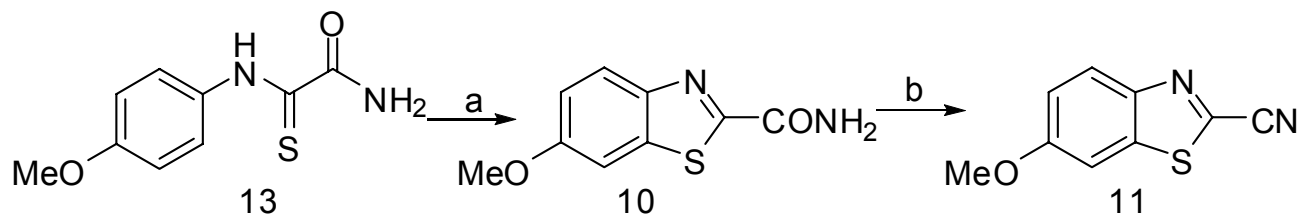

Scheme 2. Synthesis of nitrile $11 .{ }^{12}$ Reagents and conditions: (a) $\mathrm{K}_{3}\left[\mathrm{Fe}(\mathrm{CN})_{6}\right] / \mathrm{OH}^{-}$, r. t., $1 \mathrm{~h}$, $60 \%$; (c) $\mathrm{POCl}_{3}$, reflux, $1.5 \mathrm{~h}, 67 \%$.

This experimental protocol has been applied to the preparation of 5-10 g of D-luciferin (1) ${ }^{13}$ The preparation of 4-methoxythioxanilinamide 13, according to Seto et al. ${ }^{12}$ can be carried out in good yields from $p$-anisidine (4) and carbamoylthiocarbonylthioacetic acid 14. However, this compound is unstable and has to be prepared in situ, as described in detail by Bowie. ${ }^{13}$ The experimental procedure allows to prepare compound 11 from $p$-anisidine (4) with an overall 39\% yield.

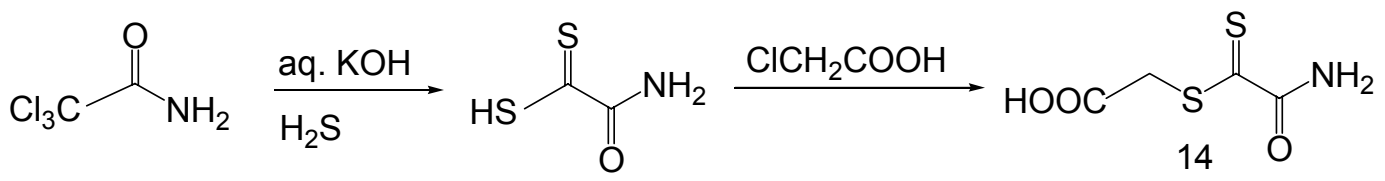<smiles>COc1ccc(NC(=S)C(N)=O)cc1</smiles>

Scheme 3. In situ preparation of carbamoylthiocarbonylthioacetic acid $\mathbf{1 4}$ and preparation of compound 13. ${ }^{12,13}$

According to another synthetic approach, 2-amino-6-methoxybenzothiazole (15) can be prepared from $p$-anisidine (4) ${ }^{14}$ and different routes can lead to 2-cyano-6-hydroxybenzothiazole (11) using a classical Sandmeyer reaction. In a first synthesis, ${ }^{14,15}$ 2-chloro-6methoxybenzothiazole (16) was prepared by reaction of compound $\mathbf{1 5}$ with nitrous acid and $\mathrm{HCl}$. Reaction of compound 16 with KCN in DMSO afforded the nitrile 11 (Scheme 4). Conditions of 
formation of 2-chloro derivative $\mathbf{1 6}$ were improved using isoamyl nitrite and copper (II) chloride in polyethylene glycol 200 as solvent ${ }^{16}$ and yields were improved to $56 \%$. More recently, the Sandmeyer reaction was carried out by direct introduction of cyanide with $\mathrm{CuCN} / \mathrm{KCN}^{17}$ and following this approach a $41 \%$ yield was obtained.

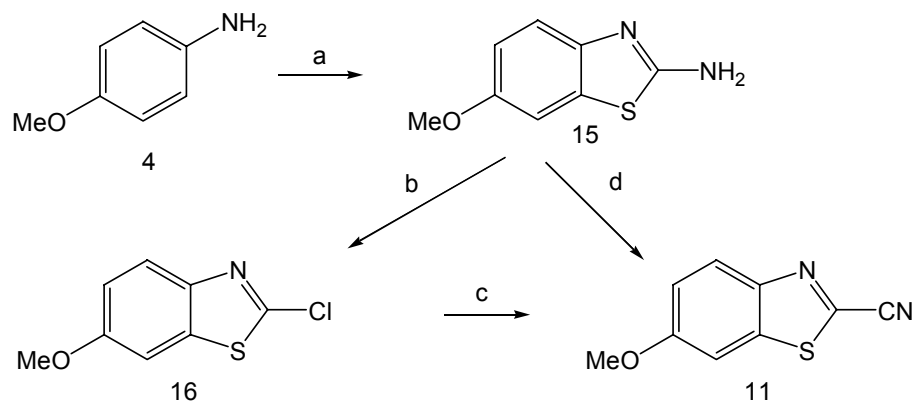

Scheme 4. Synthesis of nitrile 11 following a Sandmeyer approach from 2-amino-6methoxybenzothiazole (15). ${ }^{15-17}$ Reagents and conditions: (a) $\mathrm{KSCN}, \mathrm{Br}_{2} / \mathrm{AcOH}, 35{ }^{\circ} \mathrm{C}, 10 \mathrm{~h}$, $87 \%$; (b) $\mathrm{HNO}_{2}, \mathrm{HCl}, 0-60{ }^{\circ} \mathrm{C}, 2 \mathrm{~h}, 35-45 \%$; (c) $\mathrm{KCN} / \mathrm{DMSO}, 140{ }^{\circ} \mathrm{C}, 1 \mathrm{~h}, 40 \%$; (d) $\mathrm{HNO}_{2}$, $\mathrm{CuCN} / \mathrm{KCN}, 0^{\circ} \mathrm{C}, 1 \mathrm{~h}, 41 \%$.

Finally, it should be pointed out that, at present, the key intermediates for the synthesis of Dluciferin (1), namely 2-cyano-6-methoxybenzothiazole (11) and 2-amino-6methoxybenzothiazole (15) are commercially available (i.e., Sigma-Alrich, Europe/USA).

\section{D-luciferin analogues and derivatives as inhibitors of PpyLuc}

\subsection{D-luciferin analogues and derivatives}

A few D-luciferin (1) analogues were prepared and their inhibition towards PpyLuc was studied nearly 40 years ago. ${ }^{18}$ D-luciferin analogues included D,L-homoluciferin (17), 5-methyl and 5,5-dimethylluciferin (18a,b), deshydroxy, decarboxyluciferin, 6'-methoxyluciferin (19 a-c), 6'-amino and 6'-acetylaminoluciferin (20a,b), and 5'-chloroluciferin (21) (Figure 2). 
<smiles>[3H][In]C1CCSC(c2nc3ccc(O)cc3s2)=N1</smiles><smiles>[R]c1ccc2nc(C3=NC([R2])CS3)sc2c1</smiles>

19 a. $\mathrm{R}_{1}=\mathrm{OCH}_{3}, \mathrm{R}_{2}=\mathrm{COOH}$

b. $\mathrm{R}_{1}=\mathrm{OH}, \mathrm{R}_{2}=\mathrm{H}$

c. $\mathrm{R}_{1}=\mathrm{H}, \mathrm{R}_{2}=\mathrm{COOH}$<smiles>[R]Nc1ccc2nc(C3=NC(C(=O)O)CS3)sc2c1</smiles>

20 a. $\mathrm{R}=\mathrm{H}$

b. $\mathrm{R}=\mathrm{COCH}_{3}$<smiles>O=C(O)C1CSC(c2nc3cc(Cl)ccc3s2)=N1</smiles>

21

Figure 2. Structure of compounds 17, 18, 19, 20, and 21.

For all compounds $\mathbf{1 7 - 2 1}, \mathrm{Ki}$ values ranging from 1.0 to $3.4 \mu \mathrm{M}$ were reported ${ }^{\mathbf{1 8}}$ (Table 1) and this result was explained considering that the large hydrophobic pocket of PpyLuc active site could accommodate compounds structurally related to the natural substrate D-luciferin (1) through non-specific interactions at ATP- and luciferin-binding sites of PpyLuc active site.

Table 1. Inhibition constants (Ki) of D-luciferin analogues/derivatives 17-21 (from Denburg et $\left.a l .{ }^{18}\right)$

\begin{tabular}{cc}
\hline SUBSTRATE & Ki $\left(\mathbf{x ~ 1 0} \mathbf{~ 1 0}^{\mathbf{6}}\right)$ \\
\hline $\mathbf{1 7}$ & 2.5 \\
$\mathbf{1 8 a}$ & cis $2.9 ;$ trans 2.7 \\
$\mathbf{1 8 b}$ & 2.0 \\
$\mathbf{1 9 a}$ & $0.1^{\mathrm{a}}$ \\
$\mathbf{1 9 b}$ & 0.29 \\
$\mathbf{1 9 c}$ & 3.4 \\
$\mathbf{2 0 a}$ & 2.8 \\
$\mathbf{2 0 b}$ & 3.0 \\
$\mathbf{2 1}$ & 1.0 \\
\hline
\end{tabular}

${ }^{\mathrm{a}} \mathrm{IC}_{50}\left(\mathrm{x} 10^{6}\right)$.

D,L-homoluciferin (17) was synthesized by reaction of nitrile 12 with D,L-homocysteine that was prepared in situ by reduction of D,L-homocystine. ${ }^{1,19}$ For the synthesis of compound 18a the nitrile 12 was reacted with $\mathrm{D}$, L-threo or erythro-2-amino-3-thiobutanoic acid (cis/trans 2-methyl-D,L-cysteine), in turn obtained by debenzylation of D,L-threo or erythro-2-amino-3- 
benzylthiobutanoic acid with liquid ammonia and sodium (Scheme 5). ${ }^{\mathbf{1} 19}$ D,L- and D-5,5dimethylluciferin $\mathbf{1 8 b}$ were prepared from nitrile 12 and D,L- or D-penycillamine ${ }^{15,20}$ and reaction of the same nitrile with cysteamine afforded the compound 19b (decarboxyluciferin). ${ }^{15}$ From the reaction of nitriles 11 and 22 with D,L-cysteine, the 6-methyl ether 19a and deshydroxyluciferin $19 \mathbf{c}$ were prepared as racemates.
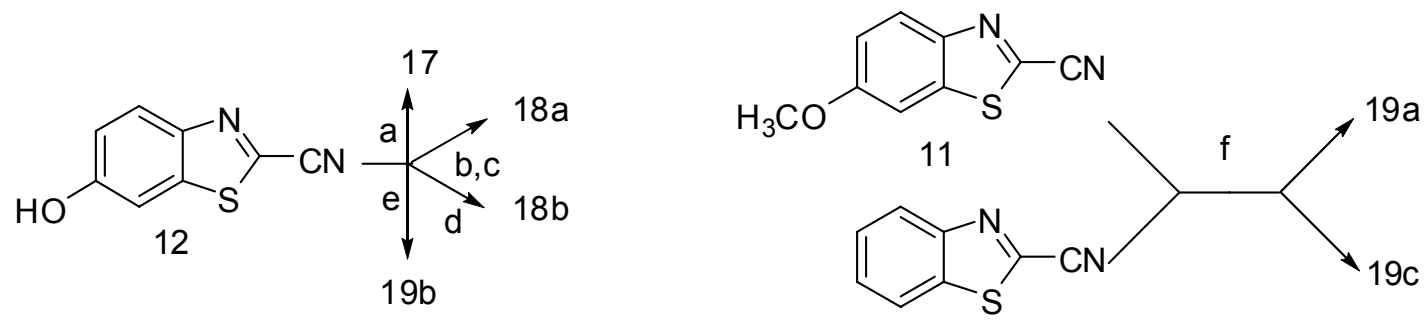

22

Scheme 5. Synthesis of compounds 17, 18 a,b, and 19a-c. ${ }^{1,15,19,20}$ Reagents and conditions. (a) D,L-homocystine, liquid $\mathrm{NH}_{3} / \mathrm{Na}, 10$ min followed by addition of $\mathbf{1 2}$ in $\mathrm{MeOH}$, r. t., 2 h, 40\%; (b) D,L-threo or erythro or erythro-2-amino-3-benzylthiobutanoic acid, liquid $\mathrm{NH}_{3} / \mathrm{Na}, 10 \mathrm{~min}$; (c) addition to (b) of $\mathbf{1 2}$ in $\mathrm{MeOH}$, r. t., $2 \mathrm{~h}, 40 \%$ for D,L-erytro; $3 \mathrm{~h}, 87 \%$ for D,L-threo; (d) D,L-penicillamine, r. t., $90.5 \%$ or D,L-penicillamine, 2 h, r. t., 35.5\%; (e) cysteamine, EtOH, reflux, $18 \mathrm{~h}, 76 \%$; (f) D,L-cystine, liquid $\mathrm{NH}_{3} / \mathrm{Na}, 10$ min followed by addition of $\mathbf{1 1}$ in $\mathrm{MeOH}$, r. t., 3 h, $89 \%$ or 22 in $\mathrm{MeOH}$, r. t., 1.5 h, $89 \%$.

D,L-6'-aminoluciferin (20a) and the corresponding acetamide 20b were prepared from the nitrile 24a or the corresponding acetamide $\mathbf{2 4 b}$ and D,L-cysteine (93\% yield for $\mathbf{2 0 a}$ and $88 \%$ for 20b). ${ }^{21}$ Nitrile 24a was synthesized from 2-chloro-6-aminobenzothiazole 23a, in turn obtained by nitration of 2-chlorobenzothiazole and reduction of the nitro derivative as previously described. ${ }^{22}$ Acetylation of 23a gave the acetamide 23b from which the $\mathrm{N}$-acetamide of 6-aminoluciferin (compound 20b) was obtained (Figure 4).

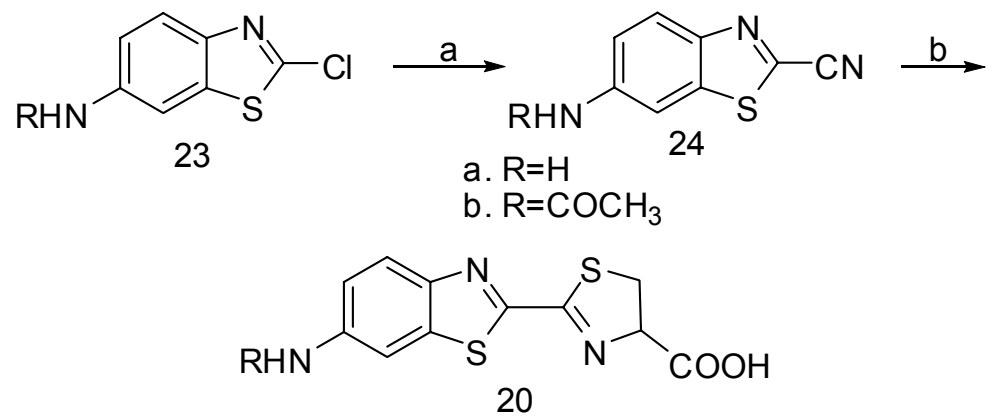

Scheme 6. Synthesis of compounds 20a,b. ${ }^{21}$ Reactions and conditions: (a) KCN in DMSO, 130 ${ }^{\circ} \mathrm{C}, 2 \mathrm{~h}, 60.5 \%$ for $\mathbf{2 3 a}$ or $78 \%$ for $\mathbf{2 3 b}$; (b) D,L-cysteine from D,L-cystine (reduction with liq. $\mathrm{NH}_{3}$ and $\mathrm{Na}$ ) and $\mathbf{2 4 a}$ (r.t., $2 \mathrm{~h}, 95 \%$ of $\left.\mathbf{2 0 a}\right)$ or $\mathbf{2 4 b}(1 \mathrm{~h}, 88 \%$ of $\mathbf{2 0 b})$. 


\subsection{Benzothiazoles structurally related to D-luciferin}

In the previously reported study concerning D-luciferin (1) analogues, ${ }^{18}$ also a few benzothiazole derivatives (compounds 25a-f) were included. These compounds are structurally related to the benzothiazole core of D-luciferin $\mathbf{1}$ and in many instances presented inhibition constants (Ki) similar to derivatives/analogues of compound 1 ( $\mathrm{Ki}$ values ranging from 25 to $58 \mu \mathrm{M}$, Table 2). It is worth pointing out that a considerable number of low-molecular weigh compounds with a great structural variety can compete with PpyLuc in a specific and non-specific manner, such as, for instance, various anhestetics ${ }^{23}$, resveratrol $(\mathrm{Ki} 2 \mu \mathrm{M}),{ }^{24}$ the $\mathrm{p} 53$-inhibitor pifithrin- $\alpha,{ }^{25}$ and lipoic acid. ${ }^{26}$<smiles>[R]c1ccc2nc([R])sc2c1</smiles>
a. $\mathrm{R}_{1}=\mathrm{R}_{2}=\mathrm{H}$
a. $R_{1}=M s \quad R_{2}=$ thiophene-2-carboxamide
b. $\mathrm{R}_{1}=6-\mathrm{OH}, \mathrm{R}_{2}=\mathrm{H}$
b. $R_{1}=M s \quad R_{2}={ }_{5}$-methylthiophene-2-carboxamide
c. $\mathrm{R}_{1}=6-\mathrm{OH}, \mathrm{R}_{2}=\mathrm{CN}$
c. $R_{1}=\mathrm{Me} \quad \mathrm{R}_{2}=$ thiophene-2-carboxamide
d. $\mathrm{R}_{1}=4-\mathrm{OH}, \mathrm{R}_{2}=\mathrm{CN}$
d. $R_{1}=$ OEt $R_{2}={ }_{2}$-methylfuran-3-carboxamide
e. $R_{1}=4-\mathrm{OCH}_{3}, \mathrm{R}_{2}=\mathrm{CN}$ f. $\mathrm{R}_{1}=\mathrm{OEt} \quad \mathrm{R}_{2}={ }_{3}$-(thiophen-2-yl)urea
f. $\mathrm{R}_{1}=6-\mathrm{Cl}, \mathrm{R}_{2}=\mathrm{CN} \quad$ g. $\mathrm{R}_{1}=\mathrm{H} \quad \mathrm{R}_{2}=(4-$ phenoxy)-1-(4-methylpiperazin-1-yl)ethanone
h. $\mathrm{R}_{1}=\mathrm{H} \quad \mathrm{R}_{2}=2$-phtalazin-1(2H)-one

Figure 3. Structure of benzothiazole derivatives 25a-f and 26a-h.

Table 2. Inhibition constants (Ki) of benzothiazole derivatives 25a-f (from Denburg et al. ${ }^{18}$ )

\begin{tabular}{cc}
\hline SUBSTRATE & $\operatorname{Ki}\left(\times 10^{6}\right)$ \\
\hline $\mathbf{2 5 a}$ & 25 \\
$\mathbf{2 5 b}$ & $-^{\mathrm{a}}$ \\
$\mathbf{2 5 c}$ & 58 \\
$\mathbf{2 5 d}$ & 26 \\
$\mathbf{2 5 e}$ & 45 \\
$\mathbf{2 5 f}$ & 28 \\
\hline
\end{tabular}

a. at $\mathrm{pH} 6.3$ the compound is as active as other benzothiazole derivatives.

This result was attributed to a non-specific interaction of the compounds with both ATPand luciferin-binding sites that characterize the ample cavity of the PpyLuc active site. In a recent paper, ${ }^{27}$ a high-throughput screening (HTS) of a library of 70.000 small molecules has been described and nearly 2.000 molecules were found to inhibit PpyLuc. Among these inhibitors, 89 active compounds were characterized by the benzothiazole core of D-luciferin (1) 
and 2,6-disubstituted benzothiazoles 26a-h (Figure 3) presented IC50 values ranging from 0.3 and $1.2 \mu \mathrm{M}$ (Table 3).

Table 3. Inhibition constants $\left(\mathrm{IC}_{50}\right)$ of benzothiazole derivatives 26a-h (from Auld et al. ${ }^{\mathbf{2 7}}$ )

\begin{tabular}{cc}
\hline SUBSTRATE & IC $_{\mathbf{5 0}}$ \\
\hline $\mathbf{2 6 a}$ & $1.1 \pm 0.4$ \\
$\mathbf{2 6 b}$ & $1.1 \pm 0.4$ \\
$\mathbf{2 6 c}$ & $0.5 \pm 0.1$ \\
$\mathbf{2 6 d}$ & $0.65 \pm 0.11$ \\
$\mathbf{2 6} \mathbf{e}$ & $1.2 \pm 0.34$ \\
$\mathbf{2 6 f}$ & $0.6 \pm 0.3$ \\
$\mathbf{2 6 g}$ & $0.3 \pm 0.1$ \\
$\mathbf{2 6 h}$ & $0.3 \pm 0.1$ \\
\hline
\end{tabular}

\subsection{Dehydroluciferin}

Dehydroluciferin [2-(6'-hydroxy-benzothiazolyl)-4-thiazole-carboxylic acid, compound 27] is a stable analogue of D-luciferin (1), since the thiazolinic ring characteristic of $\mathbf{1}$ is substituted by an aromatic thiazole moiety. Also dehydroluciferin 27 and the corresponding alcohol 28 (Figure 4) are good inhibitors of PpyLuc $(\mathrm{Ki} 1 \mu \mathrm{M}){ }^{18,28}$<smiles>[Z7]c1sc(-c2nc(C(=O)O)cs2)nc1-c1nc2ccc(O)cc2s1</smiles>

Figure 4. Structure of compounds 27 and 28.

Dehydroluciferin 27 has been initially prepared by White et al. ${ }^{9}$ boiling an alkaline solution of D-luciferin 1 under atmospheric oxygen (Scheme 7).

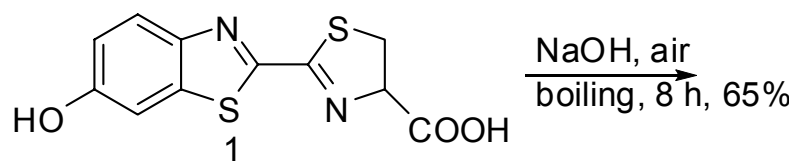<smiles>[Z7]c1nc(C(=O)O)cs1</smiles>

Scheme 7. Synthesis of dehydroluciferin 27 from D-luciferin $\mathbf{1 .}^{9}$

In the same paper, ${ }^{9}$ another synthesis of compound 27 is described and in this alternative approach, $\mathrm{H}_{2} \mathrm{~S}$ was bubbled into a solution of 2-cyano-6-methoxybenzothiazole (11) to afford the thioamide 29. From the intermediate $\mathbf{2 9}$ and methyl bromopyruvate, the derivative of 
dehydroluciferin (compound 30) was obtained and completely hydrolyzed to compound 27 with refluxing $\mathrm{HBr}$ (overall yield $16.7 \%$, Scheme 8).

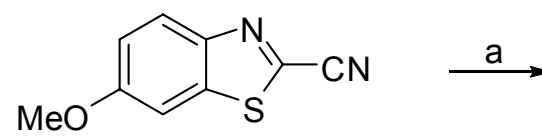

11

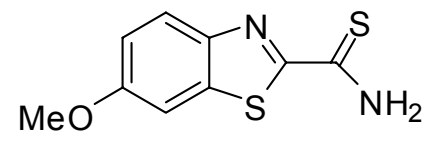

29

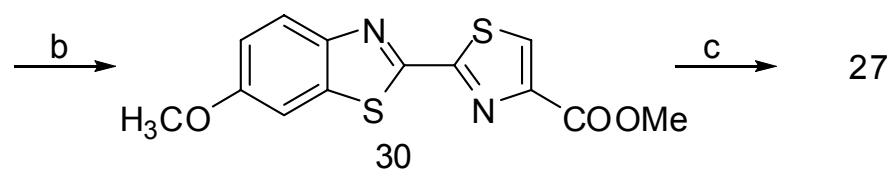

Scheme 8. Alternative synthesis of dehydroluciferin. ${ }^{9}$ Reagents and conditions: (a) $\mathrm{H}_{2} \mathrm{~S}, \mathrm{Py}$, TEA, r. t., 3 h, 95\%; (b) methyl bromopyruvate, MeOH, r. t., 22 h, 88\%; (c) HBr, reflux, 1.5 h, $20 \%$.

In another paper, ${ }^{1}$ White et al. described a similar synthesis starting from 2-cyano-6hydroxybenzothiazole 12 and preparing the methyl ester of dehydroluciferin $\mathbf{2 7}$. This avoided the harsh hydrolysis conditions for the derivative $\mathbf{3 0}^{9}$ described in Scheme 8 and overall yield of dehydroluciferin 27 was improved to $59.4 \%$. It should be mentioned that all the syntheses of compound 27 have always been carried out on milligram scale.

\subsection{5'-O-[(N-dehydroluciferyl)-sulphamoyl]-adenosine (DLSA)}

At present, the most potent PpyLuc inhibitor available is structurally related to D-luciferin $\mathbf{1}$ and to the mixed anhydride 2, that is formed by reaction of $\mathbf{1}$ with ATP. Compound $\mathbf{2}$ is the intermediate in the mechanism of formation of oxyluciferin 3 (Figure 1). The synthesis of the luciferyl adenylate $\mathbf{2 a}$ has been described by White et al. ${ }^{1}$ and consists of the reaction of Dluciferin 1 and AMP in the presence of DCC (Figure 5).

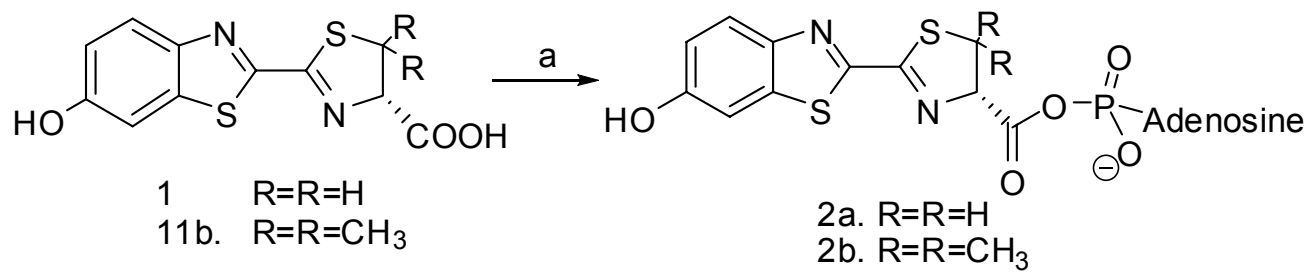

Scheme 9. Synthesis of luciferyl adenylates $\mathbf{2 a , b} .{ }^{1,20}$ Reagents and conditions: (a) DCC, AMP, DMSO, r.t., 10 min.

Compound 2a was purified by chromatography on Sephadex G-25 and the purity established by fluorescence spectroscopy and quantum yields of the reaction in the presence of PpyLuc. This 
was compared with the same assay carried out with D-luciferin (1) in the presence of ATP and $\mathrm{Mg}^{2+}$. Using the same procedure, D-5,5-dimethylluciferyl-O-adenosine-5'-monophoshate $\mathbf{2 b}$ was prepared from compound $\mathbf{1 8 b}$, purified by reverse-phase HPLC, and characterized by mass spectrometry. $^{20}$

The PpyLuc inhibitor 5'-O-[(N-dehydroluciferyl)-sulphamoyl]-adenosine (DLSA, 31) is a derivative of dehydroluciferin 27 and is an $N$-acyl sulfamate analogue of compound 2 . The synthesis of DLSA $\mathbf{3 1}^{29}$ is described in Scheme 10.

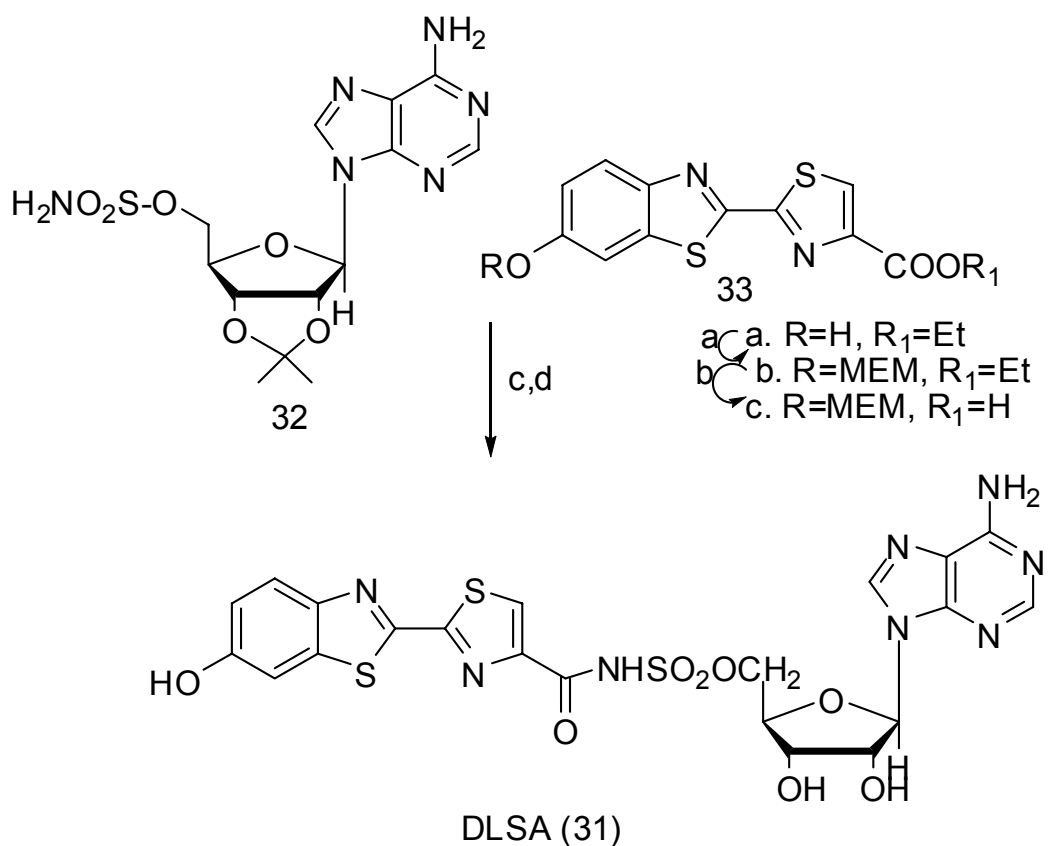

Scheme 10. Synthesis of $5^{\prime}-O-\left[(N\right.$-dehydroluciferyl)-sulphamoyl $]$-adenosine (DLSA, 31). ${ }^{29}$ Reagents and conditions: (a) THF, NaH, $0{ }^{\circ} \mathrm{C}$ to r. t., 1.5 h; MEM chloride, $0{ }^{\circ} \mathrm{C}$ to r. t., 20 h, $88 \%$; (b) $\mathrm{THF} / \mathrm{MeOH} / \mathrm{H}_{2} \mathrm{O}$ (2:1:1), $\mathrm{LiOH} / \mathrm{H}_{2} \mathrm{O}, 75{ }^{\circ} \mathrm{C}, 1.5 \mathrm{~h}, 90 \%$; (c) 33c in DMF, 1,1carbonyldiimidazole, $40{ }^{\circ} \mathrm{C}, 1.5 \mathrm{~h} ; 32$ in DMF, DBU, $40{ }^{\circ} \mathrm{C}, 90 \mathrm{~min}, 60 \%$; (d) TFA, r. t., 2 h; $\mathrm{H}_{2} \mathrm{O}$, r. t., $15 \mathrm{~min}, 69 \%$.

This multi-step synthesis started from the commercially available $2^{\prime}, 3^{\prime}-\mathrm{O}$ isopropylideneadenosine that was converted into the corresponding $5^{\prime}$-sulfamoyl derivative $\mathbf{3 2}$. $^{30}$ This intermediate was condensed with dehydroluciferin derivative 33c, in turn prepared from the ethyl ester of dehydroluciferin (compound 33a). ${ }^{1}$ Protection of the phenol group as a methoxyethoxymethyl (MEM) ether greatly improved the solubility of the derivative 33c that could be condensed with the adenosine derivative 32. The $N$-acyl sulfamate derivative DLSA so obtained was hydrolyzed by trifluoroacetic acid and DLSA was obtained as the TFA salt in 69\% yield. DLSA 31 is a reversible, non-competitive inhibitor of Ppyluc with an inhibition constant $\mathrm{Ki}$ of $34 \pm 5 \mathrm{nM}$ when compared with D-luciferin/ATP/ $\mathrm{Mg}^{2+}$. The inhibition of Ppyluc by compound $\mathbf{3 1}$ with respect to synthetic mixed anhydride $\mathbf{2}$ as the sole substrate was reversible 
and competitive with $\mathrm{Ki}=340 \pm 50 \mathrm{nM}$. This suggested that compound $\mathbf{3 1}$ is effective when binding to a unique enzymatic site available to AMP derivative 2.

It is worth noticing that the complex of DLSA 31 with the luciferase from the japanese firefly Luciola cruciata (LcrLuc) has allowed to establish the three-dimensional structure of this enzyme. ${ }^{31}$ It should be pointed out that in the case of PpyLuc, the three-dimensional structure has been solved, but in the absence of substrates or inhibitors ${ }^{32}$ and, therefore, luciferin binding-site residues have been proposed only by modeling studies. ${ }^{33,34}$

\section{Analogues and derivatives of D-luciferin as substrates of luciferases for production of bioluminescence}

\subsection{Firefly luciferases: the mechanism of light emission}

The chemical origin of multicolour bioluminescence in bioluminescent insects remains an intriguing problem, since light emissions span a wide range of wavelengths going from yellowgreen $(560 \mathrm{~nm})$ to red $(620 \mathrm{~nm}){ }^{2}$ A complex mechanism is responsible for the colour of light emission from luciferase-catalyzed reactions, as early stated examining the spectroscopic properties of substrate and product. ${ }^{35}$ It is amazing that the reaction route and the structures of substrate/product are the same for all bioluminescent insects ${ }^{36}$ and only subtle differences in the architecture of the active site are sufficient to shift the light wavelength to red. ${ }^{2}$ In some cases, the enzymatic reaction may result in the emission of light as a single bioluminescence colour, ${ }^{37}$ whereas firefly luciferases can modulate the proportion of green and red bioluminescence through a $\mathrm{pH}$-sensitive mechanism. ${ }^{38} \mathrm{~A}$ complex mechanism is responsible for the color of light emission from luciferase-catalyzed reactions. This includes the polarity of the active site of PpyLuc $^{39}$ or the presence of basic residues that are responsible for oxyluciferin tautomerization. ${ }^{40}$ Other important aspects of the mechanism can be related to the active site conformation, which may govern the angle of rotation of the two moieties of excited oxyluciferin along the $\mathrm{C} 2-\mathrm{C} 2$ ' bond, ${ }^{41}$ thus influencing the bioluminescence colors. However, all the above explanations are only a partial view of a more complex "microenvironment mechanism" that has to take in consideration the protonation state of the $\mathrm{O6}^{\prime}$ ' atom, in turn related to the polarity of the hydrogen bond that can be formed with Arg 218. ${ }^{42,43}$ Finally, the control of the resonance-based charge delocalization of the anionic keto-form of the oxyluciferin excited should be further stabilized. This could be achieved extending the $\pi$-electron system through a quinone-enolate species at a lower energy responsible for red light emission ${ }^{44}$

\subsection{Bioluminescence and optical imaging}

Bioluminescence refers to the phenomenon of light production by the enzymatic reaction of a luciferase enzyme with its substrate. Related techniques of imaging (optical imaging) are commonly used for preclinical molecular imaging in cells and small animals. ${ }^{5}$ PpyLuc is highly 
selective to convert substrate D-luciferin (1) and produces bioluminescence, which has been used for real-time, low light imaging of gene expression in cell cultures, individual cells, whole organisms, and transgenic organisms. ${ }^{45}$ PpyLuc catalyzes the emission of a yellow-green light that is attenuated by tissues in small animal imaging. Nonetheless, the enzyme is the most frequently used luciferase in molecular imaging, due to the fact that emitted light peaks 10-12 min after injection of luciferin and decreases slowly over $60 \mathrm{~min}$. In this way, a broad time window for acquiring images is provided. ${ }^{46}$ The combination of enzymatic amplification of signals from luciferase and the almost negligible background bioluminescence in vivo makes bioluminescence imaging with PpyLuc a highly sensitive method for small-animal molecular imaging. Optical bioluminescent imaging is relatively inexpensive and efficient, ${ }^{47}$ but it is suitable only for small animals and gives insufficient tomographic information. Due to absorption and scattering by the organs, the sensitivity of the method is relatively low and a high dose of the reporter probe for sufficient emission is, consequently, required. For instance, a dose of $126 \mathrm{mg} / \mathrm{kg}$ of D-luciferin (1) is needed for firefly luciferase gene imaging. ${ }^{48}$

The tissue attenuation of the light generated by PpyLuc could be overcome by a red and farred emission that should greatly improve the detection in small animal imaging. In the case of PpyLuc, the colour shift could, in principle, be achieved modifying the structure of the enzyme or that of the natural substrate, D-luciferin (1). Modification of PpyLuc structure has already produced important results, ${ }^{42}$ mainly by site-directed mutagenesis studies. According to this approach, the effect of the substitution of single amino acid residues on the wavelength of emitted light has been studied in details. ${ }^{49}$ As a significant result, several mutations led to an emitted light with an increase from to 44 to $60 \mathrm{~nm}$ with respect to the wild type enzyme. Recently, the three-dimensional structure of the luciferase from the Japanese firefly Luciola cruciata (LcrLuc) has been solved and more consistent information on the relationship between luciferase structure and colour of emitted light has become available. ${ }^{31}$

\subsection{Color-tuning of bioluminescence by modification of D-luciferin structure}

As above stated, a complex mechanism is responsible for the color of light emission from luciferase-catalyzed reactions. This involves several structural aspects of D-luciferin (1) and of the product of the enzymatic reaction, oxyluciferin $(3) .{ }^{50}$ It is worth mentioning that preliminary attempts to isolate oxyluciferin (3) from the spent enzymatic reaction led to a mixture of pigments from which no single product could be isolated. ${ }^{51}$ A similar mixture was obtained while attempting to synthesize the postulated product 3. ${ }^{1}$ Later, it has been shown that from the reaction of 2-cyano-6-hydroxybenzothiazole (12) with ethyl thioglycolate (34), dioxyluciferin 35 was formed and could be isolated only as the corresponding diacetate. ${ }^{52}$ Reaction of 2-cyano-6acetoxy-benzothiazole (36) with ethyl thioglycolate (34) yielded the 6-acetate 37, in turn converted into a stable diacetate ${ }^{53}$ (Scheme 11). 


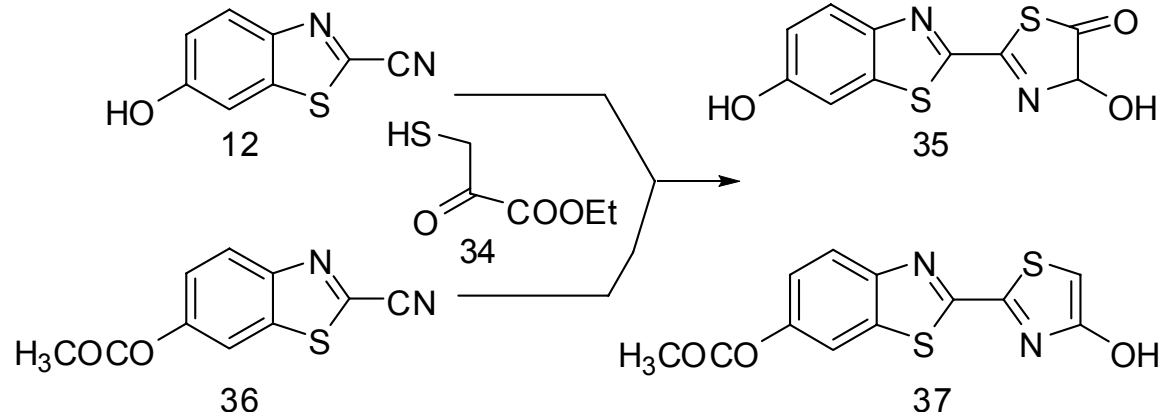

Scheme 11. Synthesis of oxyluciferin derivatives $\mathbf{3 5}$ and $\mathbf{3 7} .^{52,53}$

Similar observations on synthesis, purification and stability of oxyluciferin (3) have been reported more recently. ${ }^{54} \mathrm{~A}$ sample of oxyluciferin (3), prepared according to described protocols, ${ }^{52,53}$ was pure enough to be characterized by ${ }^{1} \mathrm{H}$ and ${ }^{13} \mathrm{C}-\mathrm{NMR}$. With this standard in hand, it was also possible to establish by HPLC the identity of the product of the PpyLuccatalyzed reaction. ${ }^{54}$

\subsubsection{Modifications of the thiazoline ring}

Modification of D-luciferin (1) structure in the thiazoline ring or in the benzothiazole moiety could, in principle, lead to a modulation of color emission. Initial experiments to establish whether an enolizable hydrogen is an essential requirement for the yellow-green/red equilibrium were carried out on 5,5-dimethyl luciferin (18b) (Figure 5).
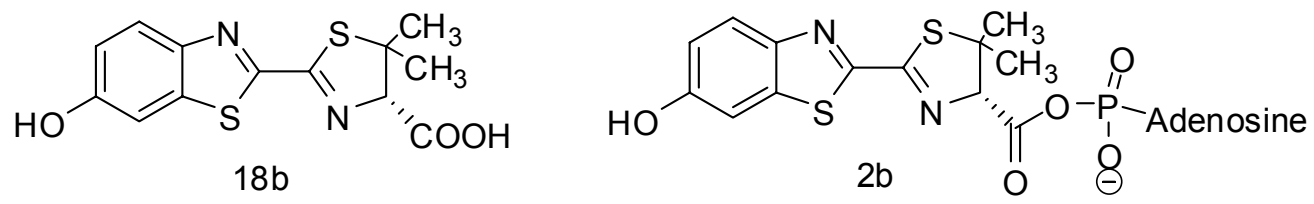

Figure 5. Structure of compounds $\mathbf{1 8 b}$ and $\mathbf{2 b .}$

The compound $\mathbf{1 8 b}$ was prepared ${ }^{15,20}$ and gave red chemiluminescence in DMSO and in the presence of a base, but was not a substrate for PpyLuc and did not produce light. The mixed anhydride with AMP (compound $\mathbf{2 b}$ ) produced a yellow-green light in the same conditions and the PpyLuc-catalyzed reaction produced light at $500 \mathrm{~nm}$. A bioluminescence at $624 \mathrm{~nm}$ was produced only when the adenylate $\mathbf{2 b}$ was the substrate of the green click beetle isozyme. ${ }^{20}$

\subsubsection{Introduction of substituents in the benzothiazole moiety of D-luciferin}

A few analogues of luciferin presenting various substituents in the benzothiazole moiety have been so far prepared and, among them, all three phenolic regioisomers of D-luciferin (1) at positions $4^{\prime}, 5^{\prime}$ and $7^{\prime}$ (compounds 38, Figure 6). ${ }^{55}$ None of the regioisomers emitted light in the 
presence of PpyLuc. A few 4'-substituted analogues of D-luciferin (1), i.e. compounds 39a,b have also been prepared using as main step the reaction of a suitable nitrile and cysteine. ${ }^{9}$

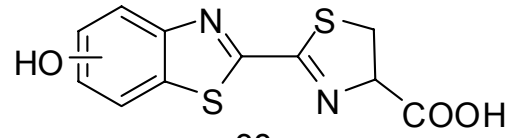

38

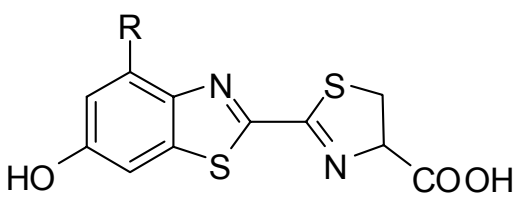

39 a. $\mathrm{R}=\mathrm{OH}$

b. $\mathrm{R}=\mathrm{CH}_{3}$

Figure 6. Structure of phenolic regioisomers of D-luciferin (compounds 38) and of 4'-substituted- D-luciferin analogues 39a,b.

The preparation of the nitriles $\mathbf{4 1}$ and $\mathbf{4 3}$ is illustrated in Scheme 12. Starting from 2,4dimethoxyaniline 40, the nitrile $\mathbf{4 1}$ is prepared following essentially the synthetic approach described by Seto. ${ }^{12}$ Reaction of the nitrile $\mathbf{4 1}$ with D,L-cysteine, under conventional conditions, ${ }^{9}$ afforded D,L-39a in 13.4\% yield from 40. ${ }^{55}$ ' -methyl-D-luciferin (39b) has been synthesized starting from 4-methoxy-2-methylaniline $\mathbf{4 2}$ that was converted into the nitrile $\mathbf{4 3}$ according to the original synthesis described by White et al. ${ }^{9}$ The critical step was the demethylation carried out with $\mathrm{PyHCl}$ that, in this specific case, proceeded with only 7\% yield and the required nitrile was obtained in $0.8 \%$ from starting aniline 42 . Also the preparation of the D-luciferin analogue $\mathbf{3 9 b}$ proceeded with low yield by reaction of the nitrile $\mathbf{4 3}$ and D-cysteine $\left(6.5 \%\right.$ yield) ${ }^{56}$<smiles>COc1ccc(N)c(OC)c1</smiles><smiles>N#Cc1nc2c(O)cc(O)cc2[se]1</smiles><smiles>COc1ccc(N)c(C)c1</smiles>

42<smiles>Cc1cc(O)cc2sc(C#N)nc12</smiles>

43

Scheme 12. Synthesis of nitriles 41 and $\mathbf{4 3}$, intermediates of 4'-substituted D-luciferin analogues 39a,b. ${ }^{55,56}$ Reagents and conditions: (a) carbamoylthiocarbonylthionoacetic acid, aq. EtOH, r.t., 48.6\%; (b) $\mathrm{K}_{3}\left[\mathrm{Fe}(\mathrm{CN})_{6}\right], \mathrm{NaOH} 1 \mathrm{M}, 10{ }^{\circ} \mathrm{C}, 30 \mathrm{~min}, 77 \%$; (c) $\mathrm{POCl}_{3}$ in Py, r.t., 2 h, 90\%; (d) $\mathrm{PyHCl}, 170-180^{\circ} \mathrm{C}, 3 \mathrm{~h}, 56 \%$; (e) ethyl oxalate, $180{ }^{\circ} \mathrm{C}, 5 \mathrm{~min}, 65 \%$; (f) $\mathrm{P}_{2} \mathrm{~S}_{5}$, xylene, reflux, $2 \mathrm{~h}$; $\mathrm{NaOH}$, r.t.; (g) $\mathrm{K}_{3}\left[\mathrm{Fe}(\mathrm{CN})_{6}\right], \mathrm{NaOH} 1 \mathrm{M},<10{ }^{\circ} \mathrm{C}, 66 \%$ from oxamate; (h) $\mathrm{SOCl}_{2}$, reflux, $2 \mathrm{~h}$, $40 \%$, (i) $\mathrm{POCl}_{3}$, reflux, $15 \mathrm{~min}, 67 \%$; (j) $\mathrm{PyHCl}, 220{ }^{\circ} \mathrm{C}$, 1h, $7 \%$. 
It has been reported that 4'-hydroxyluciferin (39a) showed bioluminescence in vitro with PpyLuc and that a red light emission was observed. However, the wavelength was not specified. 4'-Methyl-D-luciferin (39b) proved to be a substrate for PpyLuc, emitting a light with a wavelength similar to that of luciferin at about the same concentration. This result and especially the data for the bioluminescence of 4'-hydroxyluciferin (39a) confirm the hypothesis that suitable modifications of the phenyl ring in the benzothiazole core of D-luciferin (1) may influence the wavelength of emitted light in PpyLuc-catalyzed reaction.

\subsubsection{D-luciferin analogues bearing an aromatic moiety different from benzothiazole}

In all above reported structural modifications of D-luciferin, the benzothiazole aromatic ring was kept intact, because this structural framework is essential for the production of bioluminescence in the PpyLuc-catalyzed reaction. However, it has been demonstrated that light can be emitted also by compounds that replace the benzothiazole ring with other aromatic systems.

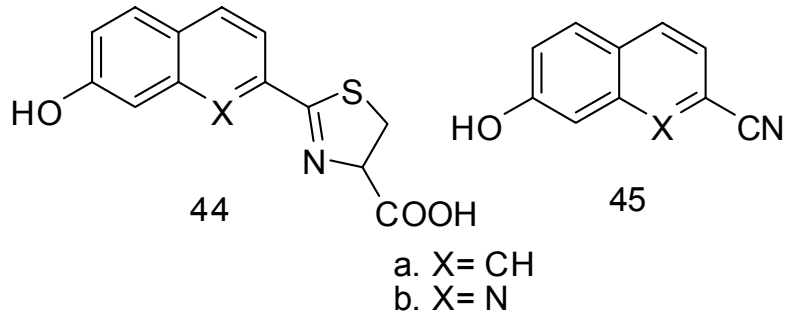

Figure 7. Structure of naphthalene and quinoline derivatives $44 \mathbf{a}, \mathbf{b}$ and structure of nitriles 45a,b.

Specifically, naphthalene or quinoline analogues of luciferin (compounds 44a,b) have been prepared from the corresponding nitriles $\mathbf{4 5 a}, \mathbf{b}^{57,58}$ (Figure 7). It has been demonstrated that both compounds are light emitters in the PpyLuc-catalyzed bioluminescence. Compound 44a is significantly blue-shifted $(524 \mathrm{~nm})$ whereas $\mathbf{4 4 b}$ emits an orange-red light at $608 \mathrm{~nm} .^{57}$ It was reported that the characteristic flash kinetics of the natural substrate were not observed for 44a,b and slower rise times to peak emission intensity were recorded. Nonetheless, the overall data suggest that by proper modification of the aromatic part of luciferin a shift of light emission towards red could be achieved.

\subsection{6'-Aminoluciferin derivatives: a new opportunity for bioluminescent assays and imaging}

6'-Aminoluciferin (20a) is the analogue of D-luciferin (1) containing an amino group at the position $6^{\prime}$ and was prepared with the acetamide $20 \mathrm{~b}$ (Figure 8) nearly thirty years ago as a racemic mixture. ${ }^{21}$ Interestingly, in the same paper a red light emission $(605 \mathrm{~nm})$ was reported in the enzymatic reaction of this substrate with PpyLuc and this bioluminescence, differently from 
luciferin, resulted to be independent of $\mathrm{pH}$. However, this finding has not been confirmed. In fact, a recent paper has reported the synthesis of D-6'-aminoluciferin (20a), selected as a Dluciferin analogue to open new opportunities for bioluminescent assays. ${ }^{59}$ The bioluminescence spectra of D-luciferin (1) and D-aminoluciferin (20a) exhibited peaks at 560 and $578 \mathrm{~nm}$, respectively, and the originally reported red emission was not confirmed. In the same paper, also the corresponding glycinamide 20c was prepared and revealed pharmacokinetic and pharmacodynamic properties that were different from those of luciferin. For instance, compound 20c showed a longer in vivo circulation time and confirmed the original assumption that derivatives of 6'-aminoluciferin (20a) can provide improvement of current imaging capabilities. It should be noted that $6^{\prime}-N$-acetyl-L-phenylalanyl)-aminoluciferin ${ }^{60,61}$ proved to be a substrate for alpha-chymotrypsin. Consequently, a coupled bioluminogenic assay was realized, based on the release of aminoluciferin by enzymatic cleavage of 6 -( $N$-acetyl-L-phenylalanyl)aminoluciferin. The released D-6'-aminoluciferin (20a) resulted in a very sensitive substrate of firefly luciferase and could easily be quantified in a luminometric assay. Amounts of chymotrypsin down to $0.3 \mathrm{ng}$ per assay were routinely determined. The usefulness of D-6'aminoluciferin (20a) for this kind of enzymatic analysis has more recently been confirmed by a set of $N$-alkylated 6 -aminoluciferins, that revealed to be bioluminescent substrates for engineered and wild-type luciferases. ${ }^{62}$ The evolution of these results has very recently brought to the preparation of peptide-bound aminoluciferin of general structure $20 \mathbf{d}$ as a tool for bioluminescence-based imaging. A recent study devoted to in vivo imaging of S-TRAILmediated tumor regression and apoptosis ${ }^{63}$ has relied on an aminoluciferin proluminescent substrate activated by caspase-3, that is the main effector of caspase in mammalian cells, expressed by cells that are still metabolically active but are programmed to die. The aminoluciferin released by the activated caspase- 3 is immediately metabolized by the luciferaseexpressing glioma cells and is detected in vivo by bioluminescent techniques. The reagent, DEVD-aminoluciferin is a thermostable proluminescent substrate that can detect apoptosis in culture. It has been prepared by reaction of aminoluciferin ${ }^{64}$ with the substrate-binding cleft of caspase-3, that recognizes a short 4-aminoacid stretch (DEVD) within protein substrates, directly N-terminal to the cleavage site. ${ }^{65}$ Other interesting and promising aminoluciferin proluminescent substrates generally indicated as compound 20d can detect in vivo enzymatic activities related to different protease markers and can find applications in homogeneous assays to measure live and dead cells in the same sample. ${ }^{66}$ Another cell-based bioluminescent assay involves the monitoring of the proteasome activity that controls the degradation of many different proteins, and of related regulatory pathways either directly or indirectly. Therefore, the proteosome activity is an interesting target of cancer therapeutics and a series of compounds structurally related to 20d have been prepared and optimized for cell permeabilization and imaging. ${ }^{67}$ 

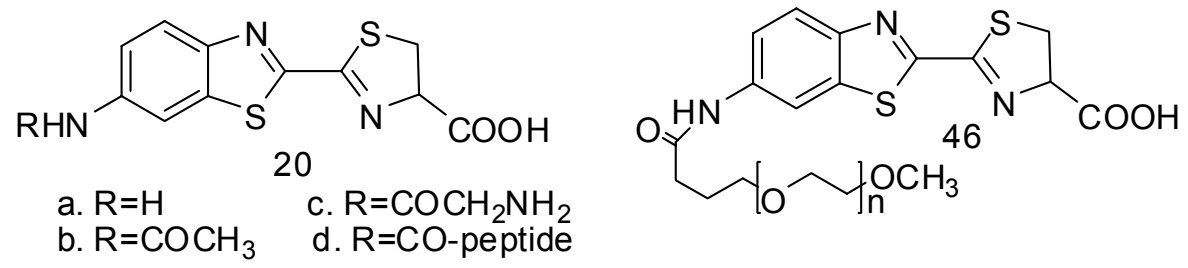

Figure 8. Structure of 6'-aminoluciferin (20a), amides 20b,c,d and PEGylated aminoluciferin 46.

Finally, a very recent application of D-6'-aminoluciferin (20a) in bioluminescent imaging technique has been investigated in order to find a solution to the problem related to D-luciferin (1) short half-life that places limits on experimental design and implementation. In order to improve the in vivo circulatory half-life of D-luciferin (1), a micro-osmotic pump can be implanted. ${ }^{68}$ Another system could rely on a polymeric carrier of the bioluminescent probe such as polyethylene glycol (PEG). This PEGylated probe could potentially be used for the imaging of tumours in vivo in murine systems for an extended period of 3-4 h after the initial injection. In this way, a simplification of execution of luciferase-based experiments would be introduced and multiple injections of luciferin could be eliminated, thus minimizing discomfort to the animals. A solution to all above problems has been proposed by preparing the PEGylated D-6'aminoluciferin (PEG-6-ADL, compound 46, Figure 8) by reaction of a PEG-carbonyl chloride and D-6'-aminoluciferin (20a). ${ }^{69}$ PEGylation of D-6'-aminoluciferin (20a) was expected to improve tumour uptake via the enhanced permeability and retention (EPR) effect $^{70}$ and by the linker-dependent hydrolysis that occurs at higher rates at slightly acidic $\mathrm{pH}$, as compared to normal physiological $\mathrm{pH}^{71}$ When PC3-Luc-bearing animals were treated with PEG-6-ADL an initial photon flux was observed in the first $30 \mathrm{~min}$ and this is consistent with data from experiments using D-luciferin (1). However, following the initial burst effect, luciferin is both cleared from circulation and consumed within the tumour, leading to a rapid decrease in the bioluminescent signal over $\sim 30-60 \mathrm{~min}$. In contrast, the PEG-6ADL light output is very low at the beginning of the time-based experiment. The signal reaches maximum intensity at about $4 \mathrm{~h}$ after the injection, at which point the signal from the non-PEGylated D-6'-aminoluciferin (20a) is at background levels. Following PEG-6ADL injection, adequate signal for imaging (i.e. $>20$ 000 photons/s) is reached at $120 \mathrm{~min}$ and remains at or above this levels for $\sim 3 \mathrm{~h}$. No detectable signal was observed following injection of non-tumour-bearing mice with PEG-6ADL. This very recent result opens fascinating perspectives, since D-6'-aminoluciferin (20a) can be used to monitor other linker systems, including those which are non-specifically hydrolysed under different intratumoural conditions, or those which are specifically hydrolysed by tumour-specific enzymes. 


\section{Conclusions}

The fascinating phenomenon of bioluminescence and the wide range of biotechnological applications in optical imaging makes the chemistry of D-luciferin and related analogues extremely interesting. This goes beyond the early expectations originally suggested by White et al. in 1971: "it is clear that chemically produced excited states are of central importance in bioluminescence; it seems moderately certain that they will also be found to be important in other areas of biology". ' The synthetic approach to the preparation of the related benzothiazole system has not moved too far from the original works dating back to nearly forty years ago. However, the chemistry involved is sound and still used for the preparation of D-luciferin and related compounds. These can be very useful as substrates for luciferases in applications such as optical imaging techniques, nowadays widely used for preclinical molecular imaging in cells and small animals. The yellow-green light emitted by the classical enzyme used for this purpose, PpyLuc, is characterized by a broad emission spectrum with a maximum at $560 \mathrm{~nm}$ and a low background bioluminescence. This makes in vivo bioluminescence imaging with PpyLuc an easy and highly sensitive method for small-animal molecular imaging. Modulation of the wavelength of the emitted light is an important target, that has mainly been achieved by site-directed mutagenesis of amino acid residues of luciferase. The same result could perhaps be obtained by chemical manipulation of D-luciferin structure, but not many transformations are possible with a relatively simple structure such as that of D-luciferin. In fact, only a few compounds have been prepared and for a reduced number of them it has been demonstrated that the light can be shifted to red in PpyLuc-catalyzed bioluminescence. However, the examples presented in this review suggest that, in addition to biochemical engineering of the enzyme, ingenuity and fantasy of synthetic organic chemistry can bring new exciting advancement in this fascinating area of research. Finally, other analogues of D-luciferin may meet expectations for new applications of in vivo optical imaging, as recently disclosed by reports that enlighten the possibility of binding a wide variety of compounds, including peptides or functionalized PEGs, to the amino group of D-6'-aminoluciferin.

\section{Acknowledgements}

This work has been supported by Università degli Studi di Milano.

\section{References and notes}

1. White, E. H.; Rapaport, E.; Seliger, H. H.; Hopkins, T. A. Bioorg. Chem. 1971, 1, 92.

2. Viviani, V. R. Cell. Mol. Life. Sci. 2002, 59, 1833.

3. Seliger, H.H.; McElroy, W.D. Proc. Natl. Acad. Sci. USA. 1964, $52,75$. 
4. Contag, C.H.; Bachmann, M.H. Annu. Rev. Biomed. Eng. 2002, 4, 235.

5. Lüker, G.D.; Lüker, K. E. J. Nucl. Med. 2008, 49, 1.

6. McElroy, W.D.; DeLuca, M.; Travis, J. Science 1967, 157, 150.

7. (a) McCapra, F. Acc. Chem. Res. 1976, 9, 201. (b) Schuster, G.B. Acc. Chem. Res. 1979, 12, 366.

8. White, E. H.; McCapra, F.; Field, G. F.; McElroy, W. D. J. Am. Chem. Soc. 1961, 83, 2402.

9. White, E. H.; McCapra, F.; Field, G. F.; J. Am. Chem. Soc. 1963, 85, 337

10. In reference 1, White et al have described in more details the preparation of D-luciferin (1) and related compounds.

11. Meroni, G.; Santaniello, E. unpublished results.

12. Seto, S.; Ogura, K.; Nishiyama, Y. Bull. Chem. Soc. Jpn. 1963, 36, 332.

13. Bowie, L. J. Method Enzymol. 1978, 57, 15.

14. Stuckwisch, G. C. J. Am. Chem. Soc. 1949, 71, 3417.

15. White, E. H.; Woelther, H.; Field, G. F.; McElroy, W. D. J. Org. Chem. 1965, 30, 2344.

16. Suzuki, N.; Nomoto, T., Kanamori, N.; Yoda, B.; Saeki, A. Biosci. Biotech. Biochem. 1993, $57,1561$.

17. Toya, Y.; Takagi, M.; Nakata, H.; Suzuki, N.; Isobe, M.; Goto, T. Bull. Chem. Soc. Jpn. 1992, 65, 392.

18. Denburg, J. L.; Lee, R. T.; McElroy, W. D. Archiv. Biochem. Biophys. 1969, 134, 381.

19. White, E.H.; Rapaport, E.; Hopkins, T.A.; Seliger, H.H. J. Am. Chem. Soc. 1969, 91, 2178.

20. Branchini, B.R.; Murtiashaw, M.H.; Magyar, R.A.; Portier, N.C.; Ruggiero, M.C.; Stroh, J.G. J. Am. Chem. Soc. 2002, 124, 2112.

21. White, E.H.; Wörther, H.; Seliger, H.H.; McElroy, W.D. J. Am. Chem. Soc. 1966, 88, 2015.

22. Katz, L. J. Am. Chem. Soc. 1951, 73, 4007.

23. (a) Moss, G.W.J.; Franks, N.P.; Lieb, W.R. Proc. Natl. Acad. Sci. USA. 1991, 88, 134. (b) Franks, N.P.; Jenkins, A.; Conti, E.; Lieb, R.; Brick, P. Biophys. J. 1998, 75, 2205.

24. Bakhtiarova, A.; Taslimi, P.; Elliman, S.J.; Kosinski, P.A.; Hubbard, B.; Kavana, M.; Kemp, D.M. Biochem. Biophys. Res. Commun. 2006, 351, 481.

25. Rocha, S.; Campbell, K. J.; Roche, K. C.; Perkins, N. D. BMC. Molecular Biology 2003, 4, 9.

26. Niwa, K.; Ohmiya, Y. Biochem. Biophys. Res. Commun. 2004, 323, 625.

27. Auld, D. S.; Southall, N. T.; Jadhav, A.; Johnson, R. L.; Diller, D. J.; Simeonov, A.; Austin, C. P.; Inglese, J. J. Med. Chem. 2008, 51, 2372 .

28. Bowie, L. J.; Horak, V.; De Luca, M. Biochemistry 1973, 12, 1845.

29. Branchini, B.R.; Murtiashaw, M.H.; Carmody, J.N.; Mygatt, E.E.; Southworth, T.L. Bioorg. Med. Chem. Lett. 2005, 15, 3860.

30. Heacock, D.; Forsyth, C. J.; Shiba, K .; Musier-Forsyth, K. Bioorg. Chem. 1996, $24,273$.

31. Nakatsu, T.; Ichiyama, S.; Hiratake, J.; Saldanha, A.; Kobashi, N.; Sakata, K. Nature 2006, 440, 376.

32. Conti, E.; Franks, N.P.; Brick, P. Structure 1996, 4, 287. 
33. Sandalova, T.P.; Ugarova, N.N. Biochemistry (Moscow) 1999, 64, 962.

34. Branchini, B.R.; Magyar, R.A.; Murtiashaw, M.H.; Anderson, S.M.; Zimmer, M. Biochemistry 1998, 37, 15311.

35. Morton, R.A.; Hopkins, T.A.; Seliger, H.H. Biochemistry 1969, 8, 1598.

36. Wood, K.V. Photochem. Photobiol. 1995, 62, 662.

37. Viviani, V.R.; Bechara, E.J.H. Photochem. Photobiol. 1995, 62, 490.

38. Seliger, H.H.; McElroy, W.D. Proc. Natl. Acad. Sci. USA 1964, 52, 75.

39. DeLuca, M. Biochemistry 1969, 8, 160.

40. White, E.H.; Branchini, B.R. J. Am. Chem. Soc. 1975, 97, 1243.

41. McCapra, F.; Gilfoyle, D.J.; Young, D.W.; Church, N.J.; Spencer, P. Bioluminescence and chemiluminescence. Fundamentals and Applied Aspects. Campbell, A. K.; Kricka, L. J.; Stanley, P. E. Eds.; John Wiley \& Sons: Chichester, 1994; pp. 387.

42. Ugarova, N.N.; Brovko, L.Y. Luminescence 2002, 17, 321.

43. Branchini, B.R.; Magyar, R.A.; Murtiashaw, M.H.; Portier, N.C. Biochemistry 2001, 40, 2410.

44. Branchini, B.R.; Southworth, T.L.; Murtiashaw, M.H.; Magyar, R.A.; Gonzalez, S.A.; Ruggiero, M.C. Biochemistry 2004, 43, 7255.

45. (a) Branchini, B. R.; Hayward, M. M.; Bamford, S.; Brennan, P. M.; Lajiness, E. J. Photochem. Photobiol. 1989, 49, 5. (b) Gandelman, O.; Allue, I.; Bowers, K.; Cobbold, P. J. Biolumin. Chemilumin. 1994, 9, 363. (c) Gates, B. J.; DeLuca, M. Arch. Biochem. Biophys. 1975, 169, 616. (d) Fontes, R.; Dukhovich, A.; Sillero, A.; Sillero, M. A. Biochem. Biophys. Res. Commun. 1997, 237, 445.

46. Paroo, Z.; Bollinger, R.A.; Braasch, D.A.; Richer, E.; Corey, D.R.; Antich, P.P.; Mason, R.P. Mol. Imaging 2004, 3, 117.

47. Sharpe, J.; Ahlgren, U.; Perry, P.; Hill, B.; Ross, A.; Hecksher-Sorensen, J.; Baldock, R.; Davidson, D. Science 2002, 296, 541.

48. Wu, J. C.; Sundaresan, G.; Iyer, M.; Gambhir, S. S. Mol. Ther. 2001, 4, 297.

49. (a) Branchini, B.R.; Magyar, R.A.; Murtiashaw, M.H.; Anderson, S.M.; Helgerson, L.C.; Zimmer, M. Biochemistry 1999, 38, 13223. (b) Branchini, B.R.; Southworth, T.L.; Murtiashaw, M,H.; Boije, H.; Fleet, S.E. Biochemistry 2003, 42, 10429. (c) Branchini, B.R.; Southworth, T.L.; Khattak, N.F.; Michelini, E.; Roda, A. Anal. Biochem. 2005, 345, 140. (d) Branchini, B.R.; Ablamsky, D.M.; Murtiashaw, M.H.; Uzasci, L.; Fraga, H.; Southworth, T.L. Anal. Biochem. 2007, 361, 253.

50. Nakatani, N.; Hasegawa, J. Y.; Nakatsuji, H. J. Am. Chem. Soc. 2007, 129, 8756.

51. Plant, P. J.; White, E. H.; Mc Elroy, W. D. Biochem. Biophys. Res. Commun. 1968, 31, 98.

52. Suzuki, N.; Sato, M.; Okado, K.; Goto, T. Tetrahedron 1972, 28, 4056.

53. Suzuki, N.; Goto, T. Tetrahedron 1972, 28, 4075.

54. Esteves da Silva, J. C. G.; Magalhaes, J. M. C. S.; Fontes, R. Tetrahedron Letters 2001, 42, 8173.

55. White, E. H.; Worther, Helmut. J. Org. Chem. 1966, 31, 1484. 
56. France, C.; Blanchot, B.; Champiat, D.; Couble, P.; Declercq, G.; Millet, J. L. J. Clin. Chem. Clin. Biochem. 1990, 28, 471.

57. Branchini, B. R.; Hayward, M.M.; Bamford, S.; Brennan, P. M.; Lajiness, E. J. Photochem. Photobiol. 1989, 49, 689.

58. Branchini, B.R. Method Enzymol. 2000, 305, 188.

59. Shinde, R.; Perkins, J.; Contag, C.H. Biochemistry 2006, 45, 11103.

60. Monsees, T.; Miska, W.; Geiger, R. Anal. Biochem. 1994, 221, 329.

61. Monsees, T.; Miska, W.; Geiger, R. J. Biolumin. Chemilumin.. 1995, 10, 213.

62. Woodroofe, C. C.; Shultz, J. W.; Wood, M. G.; Osterman, J.; Cali, J. J.; Daily, W. J.; Meisenheimer, P. L.; Klaubert, D. H. Biochemistry 2008, 47, 10383.

63. Shah, K.; Tung, C.-H.; Breakefield, X. O.; Weissleder, R. Mol. Ther. 2005, 11, 926.

64. O’Brien, M. A.; Daily, W. J.; Hesselberth, P. E.; Moravec, R. A.; Scurria, M. A.; Klaubert, D. H.; Bulleit, R.F.; Wood, K. V. J. Biomol. Screen. 2005, 10,137.

65. Rotonda, J., Nicholson, D. V.; Fazil, K. M.; Gallant, M.; Gareau, Y.; Labelle, M.; Peterson, E. P.; Rasper, D. M.; Ruel, R.; Vaillancourt, J. P.; Thornberry, N. A.; Becker, J. W. Nat. Struct. Biol. 1996, 3, 619.

66. Niles, A. L.; Moravec, R. A.; Hesselberth, P. E.; Scurria, M. A.; Daily, W. J.; Riss, T. L. Anal. Biochem. 2007, 366, 197.

67. Moravec, R. A.; O’Brien, M. A.; Daily, W. J.; Scurria, M. A.; Bernad, L.; Riss, T. L. Anal. Biochem. 2009, 387, 294.

68. Gross, S.; Abraham, U.; Prior, J. L.; Herzog, E. D.; Piwnica-Worms, D. Mol. Imaging 2007, $6,121$.

69. Chandran, S. S.; Williams, S. A.; Denmeade, S. R. Luminescence 2009, 24, 35.

70. Matsumura, Y.; Maeda, H. Cancer Res. 1986, 46, 6387.

71. Greenwald, R. B.; Choe, Y. H.; McGuire, J.; Conover, C. D. Adv. Drug Deliv. Rev. 2003, $55,217$.

\section{Author's biographies}

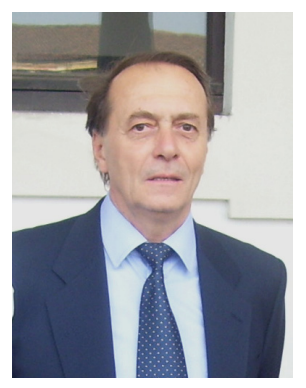

Prof. Enzo Santaniello was born in 1944. After his Laurea in Chemistry (1967) and his military service, he spent two years with a Post Doctoral fellowship at the Worcester Foundation for Experimental Biology (Worcester, Mass) under the supervision of Dr. Eliahu Caspi, working on 
synthesis and biosynthesis of estrogens. Since his return to Italy, he has spent all his academic and scientific activity in the Faculty of Medicine at the University of Milan. From 1986 he is a Full Professor of Medical Chemistry teaching Fundamentals of General Chemistry, Organic Chemistry and Biochemistry. His scientific activity has been devoted to several aspects of research in Bio-organic Chemistry, where he has used organic synthetic methodologies to solve biological problems such as biosynthesis of natural compounds or mechanisms of enzymatic catalysis. In this area, he has synthesized several biomolecules labelled with stable and radioactive isotopes. He has also been involved in researches concerning the use of biocatalysts (microorganisms and purified enzymes) in aqueous and non conventional (organic solvents) media. These methodologies have been applied to synthesis of compounds of bio-pharmaceutical interest, with particular emphasis to stereochemically pure molecules.

Recently, he has dedicated his interests to the synthesis of modified nucleosides and of biomarkers related to oxidative and nitrative stress. In the past four years, he has been involved in a project dealing with the synthesis of precursors of radiopharmaceuticals labelled with positron emitting radioisotopes for in vivo imaging. Within this project, he has been developing new syntheses of benzothiazole derivatives related to D-luciferin, the natural substrate of firefly luciferase. He has published more than 150 papers in the most qualified international journals of chemistry, biochemistry and pharmacology.

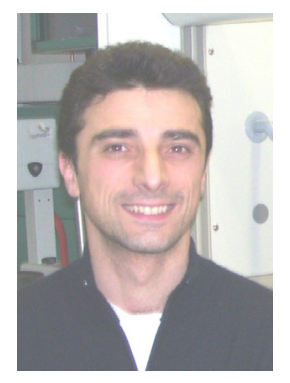

Giuseppe Meroni was born in Milan, Italy, in 1977 and obtained his Laurea in Chimica e Tecnologie Farmaceutiche (Medicinal Chemistry and Pharmaceutical Technologies) at the University of Milan, Italy, in 2005. He was defending an experimental thesis concerning the synthesis of novel isoxazole and isoxazoline derivatives and the evaluation of their pharmacological profile on $\beta$-adrenergic receptor subtypes. He is currently finishing his $\mathrm{Ph}$. D. thesis under the supervision of Professor Enzo Santaniello (Department of Medicine, Surgery and Dentistry, Faculty of Medicine, Università degli Studi di Milano) and Professor Carlo De Micheli (Department of Pharmaceutical Sciences "Pietro Pratesi", Faculty of Pharmacy, Università degli Studi di Milano). The topic of his $\mathrm{PhD}$ research project is concerned with synthesis of analogues and derivatives of D-luciferin for imaging techniques. His research interests include synthetic organic chemistry, antioxidant chemistry and biology, imaging techniques based on bioluminescence, NMR and radiopharmaceuticals. 


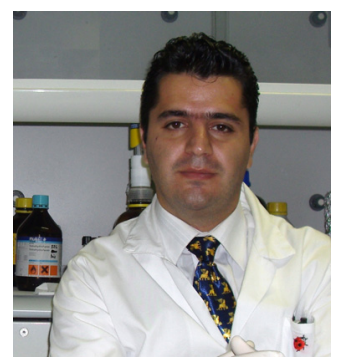

Mehdi Rajabi was born in Savadkooh, Iran, in 1981 and received his M.S. in Organic Chemistry at the Tehran Azad University in 2007 under the supervision of Dr. Shohreh Nafisi. The topic of his M.S. research project was concerned with structural analysis of anticancer drugs complexes with DNA and RNA using FTIR and UV-visible techniques. Starting from 2008, he has been working on his Ph.D program in Molecular Medicine under the supervision of Professor Riccardo Ghidoni and Professor Enzo Santaniello at the Department of Medicine, Surgery and Dentistry, Faculty of Medicine at San Paolo Hospital, University of Milan.

He is currently working on chemical synthesis of benzothiazole derivatives either related to Dluciferin, the natural substrate for luciferase, and as new potential inhibitors of human sphingosine kinase with activity against growth of different cancer cell lines. His research interests include synthetic organic chemistry and structure-activity relationship of antiproliferative agents targeting carcinoma cells. 